\title{
Estimating the Scoring Output of National Football League Teams During a Season Using Economic Production Functions
}

\author{
William Levernier \\ Georgia Southern University
}

This paper estimates a series of production functions that explain the number of points a National Football League team will score during a season based on six measures of its offensive performance. The models that are estimated are linear and Cobb-Douglas production functions, using data for each team for each season from 2000 to 2018. Additionally, separate production functions are estimated for two sub-periods to determine whether the production functions vary over time and an accuracy check is performed at the end of the paper, where each team's actual points are compared to its predicted points for the 2018 season.

\section{INTRODUCTION}

One of the most commonly used production functions in microeconomic theory is the Cobb-Douglas production function [Frank, 2010, pp. 291-292; Nicholson and Snyder, 2012, pp. 318-319; Pindyck and Rubinfeld, 2013, pp. 276-278]. This production function typically estimates a firm's output during a particular time period as a function of the amount of two inputs, capital and labor, it uses and takes the following general form,

$\mathrm{Q}=\mathrm{A} \mathrm{K} \mathrm{K}^{\alpha} \mathrm{L}^{\beta}$

This function can be transformed into the logarithmic equation,

$\ln \mathrm{Q}=\ln \mathrm{A}+\alpha \ln \mathrm{K}+\beta \ln \mathrm{L}$

Q represents the amount of output produced per time period by the firm, A is a shift factor, K represents the amount of capital utilized by the firm, and L represents the amount of labor employed by the firm. The elasticity of output with respect to capital, $E_{K}$, is given by the value of $\alpha$, and the elasticity of output with respect to labor, $\mathrm{E}_{\mathrm{L}}$, is given by the value of $\beta$.

An alternative to the Cobb-Douglas function is the linear production function, which takes the following general form,

$\mathrm{Q}=\mathrm{A}+\alpha \mathrm{K}+\beta \mathrm{L}$

The term "A" represents the intercept, and Q, K, and L are defined as they are in the Cobb-Douglas function. The marginal product of capital, $\mathrm{MP}_{\mathrm{K}}$, is given by the value of $\alpha$, and the marginal product of 
labor, $\mathrm{MP}_{\mathrm{L}}$, is given by the value of $\beta$. The marginal product of an input and the elasticity of output with respect to the input are related as follows for labor and capital, respectively; $E_{L}=M P_{L}(L / Q)$ and $E_{K}=$ $\mathrm{MP}_{\mathrm{K}}(\mathrm{K} / \mathrm{Q})$. These relationships can be written as $\mathrm{E}_{\mathrm{L}}=\mathrm{MP}_{\mathrm{L}} / \mathrm{AP}_{\mathrm{L}}$ and $\mathrm{E}_{\mathrm{K}}=\mathrm{MP}_{\mathrm{K}} / \mathrm{AP}_{\mathrm{K}}$, where $\mathrm{AP}_{\mathrm{L}}$ and $\mathrm{AP}_{\mathrm{K}}$ are the average product of labor and the average product of capital, respectively.

In the same way that a firm produces output using capital and labor, a football team scores points through its ability to possess and advance the football. Ceteris paribus, the more chances a team has to advance the football, and the more yards it gains through either running or passing the ball, the more points it will score. For purposes of estimating a football production function, the number of points scored by a team during a season is treated as its output, and the number of plays attempted by the team during the season, along with the number of yards it gains, are treated as its inputs.

This paper utilizes eight production functions, four that are linear and four that are of the CobbDouglas form. Each of the four linear production functions utilizes a different set of inputs. There is a corresponding Cobb-Douglas function for each linear function. The functions are estimated using data for all National Football League (NFL) teams for each season from 2000 through 2018. To determine whether the production functions are relatively stable over time, the functions are also estimated separately for the 2000-2009 and 2010-2018 sub-periods.

\section{THE DATA AND THE PRODUCTION FUNCTIONS}

The underlying theory of the production functions that are estimated in this paper is that a football team scores more points during a season when it has more chances to advance the ball and when it gains more yards, either through running or passing the ball. As such, the variables utilized in this paper are listed and defined in Table 1. The values for all variables were obtained from the Pro Football Reference website (www.pro-football-reference.com).

TABLE 1

DEFINITIONS OF THE VARIABLES USED IN THE PRODUCTION FUNCTIONS

\begin{tabular}{|l|l|}
\hline \multicolumn{1}{|c|}{ Variable } & \multicolumn{1}{c|}{ Definition } \\
\hline Points & The number of points scored by the team during the season. \\
\hline Total Plays & The team's number of offensive plays during the season. \\
\hline Rush Plays & $\begin{array}{l}\text { The number of offensive plays where the team attempted to run (i. e., rush) } \\
\text { the ball during the season. }\end{array}$ \\
\hline Pass Plays & $\begin{array}{l}\text { The number of offensive plays where the team attempted to pass the ball } \\
\text { during the season. }\end{array}$ \\
\hline Total Yards & $\begin{array}{l}\text { The number of total yards the team gained during the season, either through } \\
\text { running or passing the ball. }\end{array}$ \\
\hline Rush Yards & $\begin{array}{l}\text { The number of yards gained by the team during the season on running (i.e., } \\
\text { rushing) plays. }\end{array}$ \\
\hline Pass Yards & The number of yards gained by the team during the season on passing plays. \\
\hline
\end{tabular}

The mean and standard deviation of each of these variables is reported in Table 2. It can be seen in the table that the average number of points scored by a team during a season is approximately 350, or roughly 21.8 points per game. Further, an average team attempts about 1,012 plays during a season, and it attempts about 23 percent more passing plays than running plays. An average team also gains about 93 percent more yards on passing plays than on running plays during a season.

Table 2 also reveals that there are some differences between the 2000-2009 and 2010-2018 subperiods. First, the average team ran slightly more plays per season during the 2010-2018 period than during the 2000-2009 period, but the difference amounts to a little more than one play per game. Second, the number of total yards gained per season, on average, was higher during the 2010-2018 period. A third 
difference, perhaps the most interesting difference, is that the average number of running plays decreased from the earlier period to the later period, while the number of passing plays increased. This difference indicates that the NFL has become a more pass-oriented league over time. Corresponding to this difference, the average number of yards gained on running plays decreased and the number of yards gained on passing plays increased. Each team played 16 games per season during the period examined in this study, thus any differences in the means between the two sub-periods are not caused by differences in the number of games played per season.

TABLE 2

MEANS AND STANDARD DEVIATIONS OF THE VARIABLES

\begin{tabular}{|l|c|c|c|}
\hline \multicolumn{1}{|c|}{ Variable } & All Seasons & $\mathbf{2 0 0 0 - 2 0 0 9}$ & $\mathbf{2 0 1 0 - 2 0 1 8}$ \\
\hline Points & 349.51 & 338.20 & 361.99 \\
& $(71.57)$ & $(70.73)$ & $(70.53)$ \\
\hline Total Plays & $1,011.87$ & $1,003.05$ & $1,021.60$ \\
& $(46.85)$ & $(44.38)$ & $(47.64)$ \\
\hline Rush Plays & 436.65 & 444.64 & 427.82 \\
& $(51.62)$ & $(52.50)$ & $(49.22)$ \\
\hline Pass Plays & 538.50 & 522.32 & 556.37 \\
& $(59.50)$ & $(55.01)$ & $(59.24)$ \\
\hline Total Yards & $5,350.32$ & $5,178.84$ & $5,539.65$ \\
& $(634.97)$ & $(624.93)$ & $(591.62)$ \\
\hline Rush Yards & $1,820.64$ & $1,837.49$ & $1,802.05$ \\
& $(331.33)$ & $(341.75)$ & $(318.99)$ \\
\hline Pass Yards & $3,529.67$ & $3,341.36$ & $3,737.61$ \\
& $(624.44)$ & $(592.24)$ & $(593.18)$ \\
\hline $\mathrm{N}$ & 606 & 318 & 288 \\
\hline
\end{tabular}

(Standard Deviations are in Parenthesis)

\section{ESTIMATING THE PRODUCTION FUNCTIONS}

As mentioned previously, both linear production functions and Cobb-Douglas production functions are estimated in this paper. The four linear production functions that are estimated are as follows:

Points $=\mathrm{a}+\mathrm{b}$ Total Plays
Points $=\mathrm{a}+\mathrm{b}$ Rush Plays $+\mathrm{c}$ Pass Plays
Points $=\mathrm{a}+\mathrm{b}$ Total Yards
Points $=\mathrm{a}+\mathrm{b}$ Rush Yards $+\mathrm{c}$ Pass Yards

The four Cobb-Douglas production functions that are estimated are as follows:

$\ln$ Points $=\ln \mathrm{a}+\mathrm{b} \ln$ Total Plays

$\ln$ Points $=\ln \mathrm{a}+\mathrm{b} \ln$ Rush Plays $+\mathrm{c} \ln$ Pass Plays

$\ln$ Points $=\ln \mathrm{a}+\mathrm{b} \ln$ Total Yards

$\ln$ Points $=\ln \mathrm{a}+\mathrm{b} \ln$ Rush Yards $+\mathrm{c} \ln$ Pass Yards 
All eight production functions are estimated with ordinary least squares (OLS) with the covariance matrix corrected for heteroscedasticity (using the White correction in the LIMDEP econometric software package). It is expected that all explanatory variables will have a positive effect on the number of points scored by a team during a season. It is also expected that the values of the coefficients in both the linear production functions and Cobb-Douglas production functions will be approximately equal in the 20002009 and 2010-2018 sub-periods.

The regression results for the full period (2000-2018) models are shown in Table 3. The coefficients in the linear models indicate the increase in the number of points scored by a team during a season that results from a one unit increase in an independent variable (i.e., either an increase of one play or one yard), while the coefficients in the Cobb-Douglas models are elasticities, which indicate the percent increase in the number of points scored by a team during a season that results from a one percent increase in an independent variable. The R-squared values are quite large in Models 3 and 4 (the models that utilize yards, rather than plays, as independent variables), for both the linear and Cobb-Douglas models, but are relatively small in Models 1 and 2 (the models that utilize plays, rather than yards, as the independent variables). This indicates that the models that utilize yards as the independent variables have more explanatory power than the models that utilize the number of plays as the independent variables. As such, Models 3 and 4 are better football production functions than Models 1 and 2 and are likely to yield more accurate predictions of the number of points a team will score during a given season.

TABLE 3

REGRESSION RESULTS OF THE FOOTBALL PRODUCTION FUNCTIONS

\begin{tabular}{|c|c|c|c|c|c|c|c|c|}
\hline & \multicolumn{4}{|c|}{ Linear Models } & \multicolumn{4}{|c|}{ Cobb-Douglas Models } \\
\hline Variable & Model 1 & Model 2 & Model 3 & Model 4 & Model 1 & Model 2 & Model 3 & Model 4 \\
\hline Intercept & $\begin{array}{c}-285.414 \\
(-5.00)\end{array}$ & $\begin{array}{c}-338.556 \\
(-7.10)\end{array}$ & $\begin{array}{c}-147.400 \\
(-10.60)\end{array}$ & $\begin{array}{c}-166.100 \\
(-11.70)\end{array}$ & $\begin{array}{l}-7.259 \\
(-6.35)\end{array}$ & $\begin{array}{l}-6.562 \\
(-7.60)\end{array}$ & $\begin{array}{c}-6.470 \\
(-18.41)\end{array}$ & $\begin{array}{c}-5.892 \\
(-17.62)\end{array}$ \\
\hline Total Plays & $\begin{array}{c}.6275 \\
(11.12)\end{array}$ & & & & $\begin{array}{l}1.8926 \\
(11.47)\end{array}$ & & & \\
\hline Rush Plays & & $\begin{array}{c}.7807 \\
(13.72)\end{array}$ & & & & $\begin{array}{l}1.0163 \\
(13.49)\end{array}$ & & \\
\hline Pass Plays & & $\begin{array}{c}.6447 \\
(12.36) \\
\end{array}$ & & & & $\begin{array}{c}.9910 \\
(12.41) \\
\end{array}$ & & \\
\hline Total Yards & & & $\begin{array}{c}.0929 \\
(35.35)\end{array}$ & & & & $\begin{array}{l}1.4345 \\
(35.11)\end{array}$ & \\
\hline Rush Yards & & & & $\begin{array}{c}.1087 \\
(23.19) \\
\end{array}$ & & & & $\begin{array}{c}.5869 \\
(22.88) \\
\end{array}$ \\
\hline Pass Yards & & & & $\begin{array}{c}.0900 \\
(31.79)\end{array}$ & & & & $\begin{array}{c}.8992 \\
(30.77)\end{array}$ \\
\hline $\mathrm{N}$ & 606 & 606 & 606 & 606 & 606 & 606 & 606 & 606 \\
\hline R-Squared & .169 & .242 & .679 & .686 & .175 & .243 & .677 & .677 \\
\hline
\end{tabular}

Note: The t-statistics are shown in parenthesis. All coefficients are statistically significant at the .01 level. There were 30 teams in the NFL during the 2000 and 2001 seasons but 32 teams each season thereafter.

Model 1 of the linear models indicates that each additional offensive play causes a team to score an additional .63 points, ceteris paribus. Model 2 indicates that each additional running play leads to more points scored than each additional passing play, .78 points compared to .64 points, ceteris paribus. Model 3 indicates that each additional yard a team gains, either by running or passing the ball, causes an increase in .09 points scored, and Model 4 indicates that each additional yard gained by running causes a slightly larger increase in points scored than each additional yard gained by passing, . 11 compared to .09 .

In the Cobb-Douglas models, the results of Model 1 indicate that a one percent increase in a team's number of offensive plays during a season increases its number of points by 1.9 percent. Model 2 indicates a one percent increase in a team's number of passing plays during a season increases the number 
of points it scores by about one percent, which is approximately the same affect that running plays have on a team's scoring. Model 3 indicates that when a team increases the total yards it gains during a season by one percent, its scoring increases by roughly 1.4 percent. Model 4 indicates that a one percent increase in a team's passing yardage increases its scoring by about .9 percent, while an increase in a team's running yardage of one percent increases its scoring by a much smaller .6 percent. Thus, the only two factors that are relatively elastic are a team's total number of plays and the total number of yards it gains during the season. The remaining variables are either inelastic or approximately unit elastic.

Table 4 reports the regression results of Model 4 for both the linear production function and the Cobb-Douglas production function for two specific sub-periods, 2000-2009 and 2010-2018. In both production functions the coefficients in the latter period are larger than those in the former period, indicating that a yard gained by a football team, either by running the ball or by passing the ball, had a larger positive effect on the points it scored in a season during the 2010-2018 period than during the 2000-2009 period. The differences in the magnitudes of the coefficients are relatively small, however, with a given coefficient being less than 9.0 percent larger in the 2010-2018 regressions than in the 20002009 regressions. As such, the production functions are relatively constant between the two periods.

TABLE 4

PRODUCTION FUNCTION RESULTS, MODEL 4, BY SUB-PERIOD

\begin{tabular}{|l|c|c|c|c|}
\hline & \multicolumn{2}{|c|}{ Linear Model } & \multicolumn{2}{c|}{ Cobb-Douglas Model } \\
\hline \multicolumn{1}{|c|}{ Variable } & $\mathbf{2 0 0 0 - 2 0 0 9}$ & $\mathbf{2 0 1 0 - 2 0 1 8}$ & $\mathbf{2 0 0 0 - 2 0 0 9}$ & $\mathbf{2 0 1 0 - 2 0 1 8}$ \\
\hline Intercept & -158.391 & -196.339 & -5.823 & -6.499 \\
& $(-8.43)$ & $(-8.56)$ & $(-12.69)$ & $(-12.87)$ \\
\hline Rush Yards & .1049 & .1144 & .5894 & .5915 \\
& $(16.62)$ & $(16.62)$ & $(16.68)$ & $(16.26))$ \\
\hline Pass Yards & .0909 & .0942 & .8896 & .9674 \\
& $(22.66)$ & $(21.04)$ & $(21.55)$ & $(21.31)$ \\
\hline $\mathrm{N}$ & 318 & 288 & 318 & 288 \\
\hline R-Squared & .690 & .671 & .678 & .662 \\
\hline
\end{tabular}

Note: The t-statistics are shown in parenthesis. All coefficients are statistically significant at the .01 level.

\section{COMPARING THE PREDICTIVE ACCURACY OF THE LINEAR PRODUCTION FUNCTION TO THE COBB-DOUGLAS PRODUCTION FUNCTION}

The final part of the analysis involves comparing the predictive accuracy of Model 4 of the linear production function to that of Model 4 of the Cobb-Douglas production function. For this comparison, the regressions for Model 4 are re-estimated for both production functions using data from the 2000-2017 period, rather than from the 2000-2018 period. The coefficients from these re-estimated regressions are then used to predict the number of points each of the 32 teams will score during the 2018 season, given the number of yards actually gained by the team on passing plays and on running plays during the season. The re-estimated regression equations for the linear production function and the Cobb-Douglas production function, respectively, are:

Points $=-164.65+.1079$ Rush Yards +.0901 Pass Yards

Points $=.00279 \times$ Rush Yards ${ }^{.5857} \mathrm{x}$ Pass Yards ${ }^{8988}$

Table 5 reports the actual number of points and the predicted number of points for each NFL team during the 2018 season. The absolute error is the absolute value of the team's actual points minus its predicted points. 
TABLE 5

ACTUAL VERSUS PREDICTED POINTS, 2018 SEASON, BY TEAM

\begin{tabular}{|c|c|c|c|c|c|}
\hline \multirow[b]{2}{*}{ Team } & \multirow[b]{2}{*}{$\begin{array}{l}\text { Actual } \\
\text { Points }\end{array}$} & \multicolumn{2}{|c|}{ Linear Function } & \multicolumn{2}{|c|}{ Cobb-Douglas Function } \\
\hline & & $\begin{array}{c}\text { Predicted } \\
\text { Points }\end{array}$ & $\begin{array}{c}\text { Absolute } \\
\text { Error }\end{array}$ & $\begin{array}{c}\text { Predicted } \\
\text { Points }\end{array}$ & $\begin{array}{c}\text { Absolute } \\
\text { Error }\end{array}$ \\
\hline Arizona Cardinals & 225 & 207.3 & 17.7 & 216.8 & 8.2 \\
\hline Atlanta Falcons & 414 & 424.1 & 10.1 & 412.4 & 1.6 \\
\hline Baltimore Ravens & 389 & 419.1 & 30.1 & 419.1 & 30.1 \\
\hline Buffalo Bills & 269 & 301.0 & 32.0 & 298.7 & 29.7 \\
\hline Carolina Panthers & 376 & 411.2 & 35.2 & 414.7 & 38.7 \\
\hline Chicago Bears & 421 & 365.4 & 55.6 & 366.7 & 54.3 \\
\hline Cincinnati Bengals & 368 & 313.1 & 54.9 & 314.1 & 53.9 \\
\hline Cleveland Browns & 359 & 400.4 & 41.4 & 401.8 & 42.8 \\
\hline Dallas Cowboys & 339 & 365.7 & 26.7 & 367.0 & 28.0 \\
\hline Denver Broncos & 329 & 373.8 & 44.8 & 375.2 & 46.2 \\
\hline Detroit Lions & 324 & 336.5 & 12.5 & 335.9 & 11.9 \\
\hline Green Bay Packers & 376 & 396.8 & 20.8 & 392.3 & 16.3 \\
\hline Houston Texans & 402 & 393.9 & 8.1 & 396.3 & 5.7 \\
\hline Indianapolis Colts & 433 & 422.4 & 10.6 & 418.1 & 14.9 \\
\hline Jacksonville Jaguars & 245 & 301.2 & 56.2 & 302.7 & 57.7 \\
\hline Kansas City Chiefs & 565 & 481.7 & 83.3 & 480.6 & 84.4 \\
\hline Los Angeles Chargers & 428 & 405.6 & 22.4 & 406.7 & 21.3 \\
\hline Los Angeles Rams & 527 & 481.9 & 45.1 & 491.7 & 35.3 \\
\hline Miami Dolphins & 319 & 284.0 & 35.0 & 285.8 & 33.2 \\
\hline Minnesota Vikings & 360 & 359.9 & 0.1 & 352.0 & 8.0 \\
\hline New England Patriots & 436 & 438.5 & 2.5 & 443.0 & 7.0 \\
\hline New Orleans Saints & 504 & 417.8 & 86.2 & 421.3 & 82.7 \\
\hline New York Giants & 369 & 377.8 & 8.8 & 374.1 & 5.1 \\
\hline New York Jets & 333 & 295.3 & 37.7 & 296.9 & 36.1 \\
\hline Oakland Raiders & 290 & 348.8 & 58.8 & 346.7 & 56.7 \\
\hline Philadelphia Eagles & 367 & 389.7 & 22.7 & 381.7 & 14.7 \\
\hline Pittsburgh Steelers & 428 & 442.2 & 14.2 & 419.2 & 8.8 \\
\hline San Francisco 49ers & 342 & 388.8 & 46.8 & 390.3 & 48.3 \\
\hline Seattle Seahawks & 428 & 390.0 & 38.0 & 380.0 & 48.0 \\
\hline Tampa Bay & 396 & 461.2 & 65.2 & 441.4 & 45.4 \\
\hline Tennessee Titans & 310 & 321.9 & 11.9 & 320.0 & 10.0 \\
\hline Washington Redskins & 281 & 298.8 & 17.8 & 300.1 & 19.1 \\
\hline Total & & & $1,053.2$ & & $1,004.3$ \\
\hline
\end{tabular}

The last row of the table is the sum of the absolute errors and it indicates that the Cobb-Douglas model has slightly more accurate predictions regarding a team's scoring in 2018 than does the linear model. The total of the absolute errors is larger for the linear model, 1,053 compared to 1,004 for the Cobb-Douglas model. Since there were 32 teams in the NFL in 2018, the average difference in the predictive errors of the two models is about 1.5 points per team. This is a very small difference, considering the average team scored nearly 374 points during the 2018 season. 


\section{CONCLUSION}

This paper has estimated two general forms of football production functions, using data from all National Football League teams for the 2000 through 2018 seasons. The two general production functions are the linear production function and the Cobb-Douglas production function, one of the most commonly used production functions in microeconomic theory. The production functions obtained in this study indicate that the number of points a team scores during a season is positively affected by the number of plays it runs and by the number of yards it gains on both running plays and passing plays. The results of the study also suggest that the Cobb-Douglas form of the production function yields slightly more accurate predictions of how many points a team will score during a season than the linear production function, but the difference in the predictive accuracy of the two functions is very small.

\section{REFERENCES}

Frank, R. H. (2010). Microeconomics and Behavior. New York, NY: Mc-Graw Hill Irwin.

Nicholson, W., \& Snyder, C. (2012). Microeconomic Theory: Basic Principles and Extensions. Mason, $\mathrm{OH}$ : Southwestern.

Pindyck, R. S., \& Rubinfeld, D. L. (2013). Microeconomics. Boston, MA: Pearson. 